\title{
Surgical Oncology at the Crossroads: the Future is Now
}

\author{
Raphael E. Pollock, MD, PhD \\ Department of Surgical Oncology, The University of Texas M.D. Anderson Cancer Center, Box 444, 1515 Holcombe Blvd, Houston, \\ TX 77030, USA
}

I am aware that I would not have had this opportunity to serve as your President this past year were it not for the help of many others, and I wanted to recognize several individuals specifically. My surgical residency years in Chicago enabled me to work closely with David Skinner at the University of Chicago and Steven Economou at Rush University (Fig. 1). Dr. Skinner was a master of clarity in thought, articulation, and purposeful accomplishment. Dr. Economou was the first to show me the cognitive and technical aspects of our specialty. A practitioner of multidisciplinary oncology care long before the concept came into vogue, Dr. Economou was proof positive that cancer could be thought through and beaten back by knowledge coupled to an "eloquent scalpel". Dr. Economou was the first to stimulate, and then encourage, my aspirations to become a surgical oncologist, and for this I will always be grateful.

During my fellowship at M.D. Anderson, I was very fortunate to train under Dr. Richard Martin (Fig. 2), one of the unsung heroes of American surgery. Of all the many surgeons with whom I have ever worked, Dr. Martin was unique in possessing unsurpassed technical surgical brilliance coupled to total-and at times even self-effacing-personal humility. Dr. Martin's unflagging devotion to the cancer patient is why he was universally revered by colleagues and trainees alike. Dr. Martin kindled my interest in soft tissue sarcoma, and supported my

Received July 31, 2007; accepted August 10, 2007; published online: January 3, 2008.

Address correspondence and reprint requests to: Raphael E. Pollock, MD, PhD; E-mail: rpollock@manderson.org

Published by Springer Science+Business Media, LLC @ 2007 The Society of Surgical Oncology, Inc. aspirations as a clinician-investigator during my fellowship and initial faculty years. Dr. Martin was succeeded as Chairman by Dr. Balch (Fig. 3). Charles has had an enduring impact on my commitment to academic surgical oncology - as is also the case for so many of us here today. His energy, positive attitude, and personal resilience are remarkable; I am lucky to have him as my friend.

I am particularly grateful to the faculty of the Department of Surgical Oncology at M.D. Anderson (Fig. 4). Their loyalty to our patients, our trainees, our academic pursuits, and to our department is unflagging - my thanks to all of you for this. I have been privileged to participate in training more than 150 fellows during my time at M.D. Anderson (Table 1). We are proud of the accomplishments of this amazing group, and are confident that they will move this great enterprise along much farther than the point we have reached today. My family of origin has also had a profound impact. Growing up as the second of five children taught me much about negotiation and compromise. My father, the first $\mathrm{MD} / \mathrm{PhD}$ that I ever met, was a most important mentor for lessons about how to live purposefully, how to aspire, and how to survive in the academic environment. My greatest treasure is my own family, and between raising our five children, faculty life at M.D. Anderson, and our shared sarcoma research program, my wife Dina and I keep pretty busy.

It was difficult to decide what to talk about today, acutely aware that I am speaking to my colleagues, trainees - current and former - and my friends: all of you hope to come away from our conversation with something of importance and meaning. I decided not to speak of insights gained from my various roles as a 


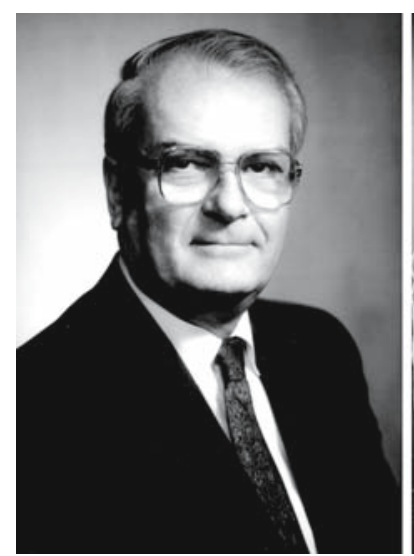

David Skinner

Univ. of Chicago

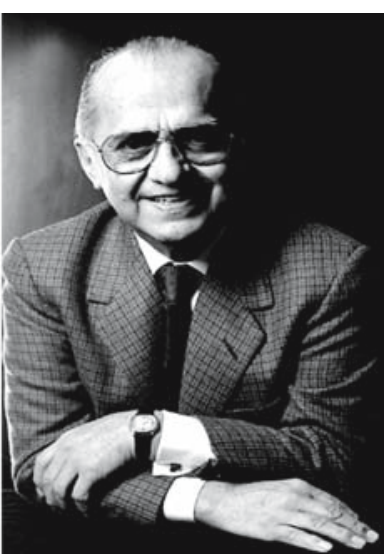

Steven Economou Rush University
FIG. 1. David Skinner, University of Chicago. Steven Economou, Rush University.

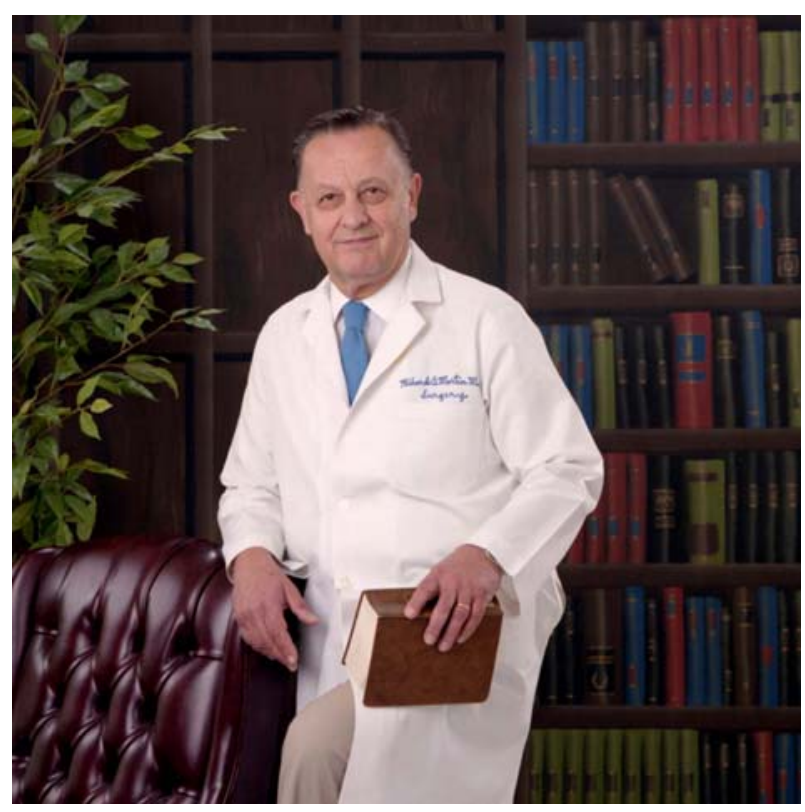

Richard G. Martin

FIG. 2. Richard Martin, M.D. Anderson Cancer Center.

soft-tissue sarcoma surgeon, a department chairman, a laboratory investigator, or a mentor and educator, although I am very fortunate to have experienced all of these. Instead, today I am speaking as your President, and I began thinking about this opportunity and its responsibilities at about this time last year. To be honest, at that point I was thinking more about the opportunity to be creative than about the weight of the responsibility. After the Society of Surgical Oncology (SSO) meeting last year, when I returned to Houston, I opened up a file labeled "SSO Address"

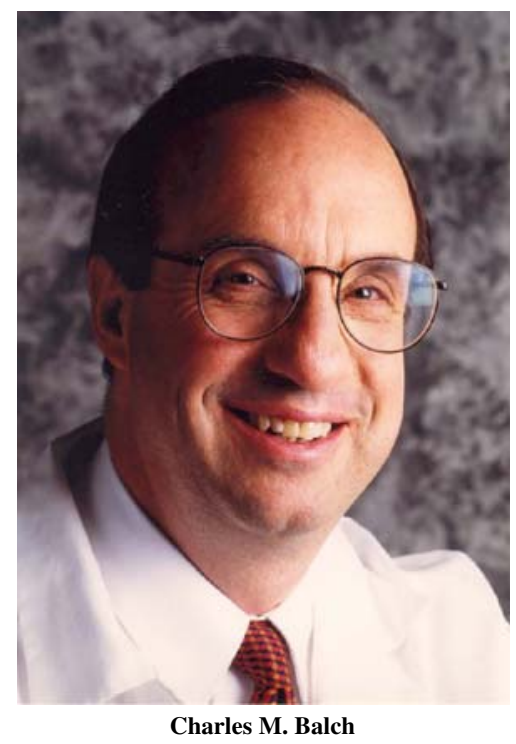

FIG. 3. Charles M. Balch, Johns Hopkins University.

and threw in interesting articles, as well as my own occasional insomnia-fueled scribbles of half-baked ideas, knowing that I had the summer months to work on this project, which led to postponement until after the American College of Surgeons meeting last October, and then came the end-of-the-year holiday season, and then...well, then there really was not much more time left, and reading through the contents of my SSO talk file did not lead to flashes of insight that might be molded into a coherent whole. So I looked back on this year, serving as your President, and reflected that it has been a time of exploration against the backdrop of this remarkable professional honor, quite likely the highest that I will ever receive. I realized that sharing my internal dialogue about how we might make a difference for our Society and our specialty, and what we could do on behalf of this good cause-I came to understand that this should be the "stuff" of my SSO presidential address. So I have decided to use this opportunity to offer to you a report, an interim report to be sure, of this year-long personal and professional journey. I want to use these moments to focus your attention on four concerns that -if handled effectively - contain the possibility for genuine growth of our Society, but if ignored could have serious negative repercussions. Together, we can consider some first steps that might be taken; for, as has wisely been advised, "control your own destiny, unless you would rather have someone else do it for you".

One such concern, moving rapidly to the front burner, is the looming crisis in general surgical 
Department of Surgical Oncology: 2007

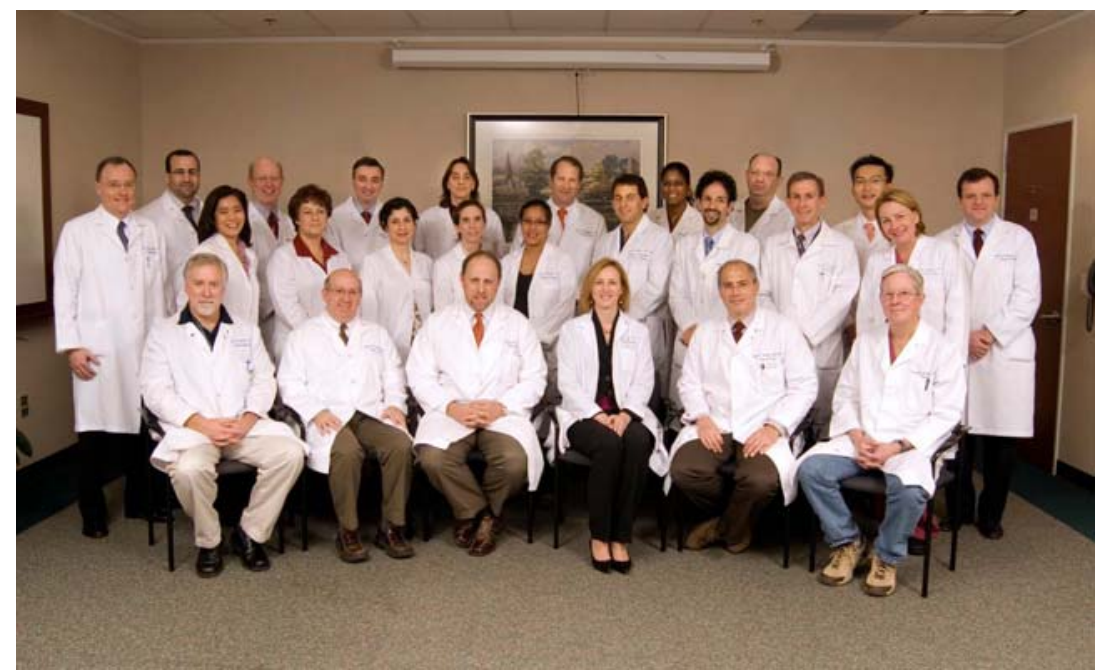

FIG. 4. Department of Surgical Oncology: 2007.

TABLE 1. Surgical Oncology Fellows: 1984-2008

\begin{tabular}{|c|c|c|c|c|c|}
\hline Abdalla, Eddie & Broadwater, John & Fleming, Jason & Laronga, Christine & Pederson, Lee & Spitz, Francis \\
\hline Ahearne, Paul & Byrd, David & Fleming, Richard & Leach, Steven & Peoples, George & Staley, Charles \\
\hline Ahmad, Syed & Camp, Ernest & Fournier, Keith & Lee, Jeffrey & Pezzi, Christopher & Stotter, Anne \\
\hline Albo, Daniel & Carlson, Grant & Frederick, Wayne & Lenert, Jeffrey & Porter, Geoffrey & Sussman, Jeffrey \\
\hline Aloia, Thomas & Carragher, Angela & Fuhrman, George & Ley, Phillip & Portera, Charles & Swanson, Richard \\
\hline Al-Refaie, Waddah & Choi, Eugene & Gannon, Christopher & Lim, Sherry & Raut, Chandrajit & Tada, Hiroomi \\
\hline Amos, Keith & Chun, Yun Shin & Gershenwald, Jeffrey & Lowy, Andrew & Rawlings, Maurice & Talamonti, Mark \\
\hline Anaya, Daniel & Cormier, Janice & Gonzalez, Ricardo & Lugo, Raul & Reilly, James & Tanabe, Kenneth \\
\hline Archer, Stephen & Couture, Jean & Grau, Ana & McBath, Mark & Rodgers, Steven & Thompson, William \\
\hline Badgwell, Brian & Curley, Steven & Gray, Keith & McCready, David & Roseman, Barry & Tseng, Jennifer \\
\hline Barnes, George & Cusack, James & Grubbs, Elizabeth & McMasters, Kelly & Ross, Merrick & Tuttle, Todd \\
\hline Barnett, Carlton & Dackiw, Alan & Gutman, Haim & Meric, Funda & Rousseau, Dennis & Tyler, Douglas \\
\hline Barrera, Emilo & Daneker, George & Hardy, Mark & Meterissian, Sarkis & Royal, Richard & Wang, Thomas \\
\hline Bauer, Todd & Daniel, James & Heaton, Keith & Midis, Gergory & Ryan, Bernandette & Watkins, Kevin \\
\hline Bedrosian, Isabelle & Davidson, Bradley & Henderson, Michael & Miller, Alexander & Scaife, Courtney & Wayne, Jeffrey \\
\hline Beech, Derrick & Delman, Keith & Hoagland, Janet & Mittendorf, Elizabeth & Scoggins, Charles & Whitworth, Pat \\
\hline Bell, John & Edwards, Michael & Hurd, Thelma & Mullen, John & Shumate, Charles & Wood, William \\
\hline Berger, David & Ehlers, Richard & Hwang, Rosario & Newman, Lisa & Skibber, John & Wray, Curtis \\
\hline Berman, Russell & Ehrenfried, John & Izzo, Francesco & Ng, Eng-Hen & Sloan, David & Yahanda, Alan \\
\hline Bilimoria, Malcolm & Ellis, Lee & Kahky, Michael & Nieweg, Omgo & Smith, David & Yeatman, Timothy \\
\hline Blazer, Dan & Esgro, Joseph & Katz, Mathew & Parikh, Alexander & Smith, Jeffrey & Yen, Tina \\
\hline Bold, Richard & Esnaola, Nestor & Kesmodel, Susan & Pawlik, Timothy & Smith, Mark & Zager, Jonathan \\
\hline Bouvet, Michael & Evans, Douglas & Kokotsakis, John & Pearlstone, David & Solorzano, Carmen & \\
\hline Breslin, Tara & Feig, Barry & Lambert, Laura & Pearson, Adrian & Souba, Wiley & \\
\hline
\end{tabular}

manpower. We can continue to lumber along, or realize that we need a strategy to cope with the threat. This threat is real, if only because most of our members are certified by the American Board of Surgery (ABS), and all of the SSO-accredited surgical oncology fellowship training programs require that candidates be ABS eligible or certified. The overall number of general surgeons in the US has stagnated for more than 30 years (Fig. 5). Why has this happened? The answer is multifactorial. Nonetheless, we need to scrutinize this problem so that we can tease out and change those parts where we might have an impact. One underlying factor is that US population growth has simply outstripped our ability to train surgeons, and this problem will only get worse as the baby boomers move into the cancer-incidence agebrackets over the next several years. Cancer will replace cardiovascular disease as the number one killer of Americans sometime over the next several years, and there will be more than twice as many people aged 65 or older in the US 10 years from now-this is our demographic reality. Medical workforce short- 


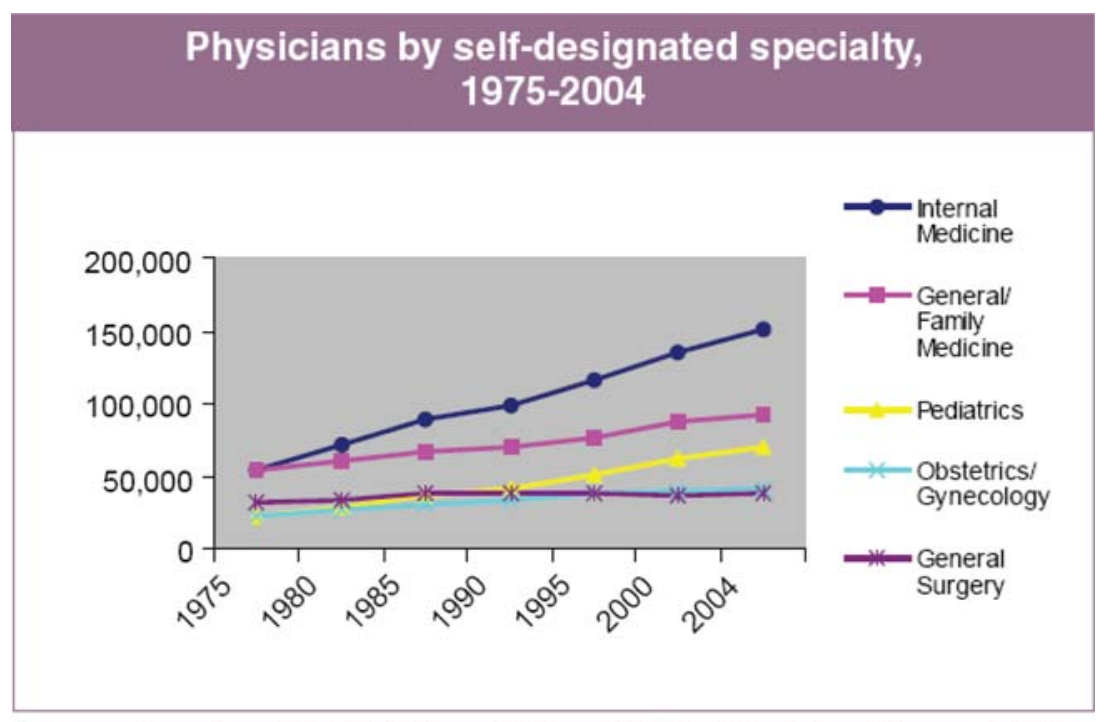

Source: American Medical Association (AMA): Physician Characteristics and Distribution in the US, 2006 edition.
FIG. 5. Source: American Medical Association (AMA): physician characteristics and distribution in the US, 2006 edition. ages are emerging in many healthcare sectors, but appear to be amongst the worst in surgery, where the per capita number of general surgeons is at a 50 -year low. Not only is the rate of general surgical growth slower than that of the general population, but it is also markedly less in absolute terms than that of nonsurgical medical specialties. Add to this picture the unresolved medical liability crisis, the accelerating time demands of medical documentation, and the erosion in all types of payer compensation - is anyone surprised that the average retirement age for US general surgeons now hovers in the mid-50s?

On the macro level, the Federal government has supported the opening of four new medical schools by 2009 , the first such expansion since 1982 . But will this take care of the problem? Obviously not, and I suggest we can help, on a daily basis, by looking at how we work as role models and mentors for our medical students and surgical trainees. Our trainees are confronted by many new challenges that most of us never faced: massive educational debts, literally compounded by the length of time needed to become "fully trained" - and how long will that take in this "Brave New World" of the 80-hour work-week? These young people are appropriately questioning how much additional time beyond residency will be needed to become a truly autonomous surgeon, and our positive mentoring (or lack thereof) will go a long way towards resolving (or exacerbating) these concerns.

Most medical students decide on their specialty during their third year clinical clerkships. The shorter length of surgical rotations decreases student exposure to surgical residents and attendings, which further erodes our contact time as mentoring role models. As reported in 2004 by the American Surgical Association Blue Ribbon Committee, ${ }^{1}$ students who received effective mentoring were much more likely to opt for surgical careers and less likely to be as concerned about time-commitment issues, call schedules, debt loads etc. It is particularly gratifying that the dip in general surgery residency applicant numbers seen earlier this decade has now been corrected, and almost all training slots are currently being filled. So here is idea number one: we must continue in our strong efforts to be the best possible role models for our students and our residents - and those of us in positions of authority should reinforce a culture in our departments where the quality of these mentoring efforts are recognized and rewarded in our evaluation and promotion systems.

There are other actions that we can take to help strengthen perceptions about surgical training, the entry point into a surgical oncology career. Here is idea number two: what about targeted outreach programs that would enable medical students to attend the SSO annual meeting, perhaps by funding a substantial number of student travel scholarships? These students are our germline DNA, and they are worthy of our active cultivation. We also need to better understand the optimal size of the surgical oncology manpower pool. Consider the 2006 fellowship match results (Table 2). Nationally, is there perhaps too much capacity for CVT training and not enough for surgical oncol- 
TABLE 2. 2006 Specialty Fellowship Match Results

\begin{tabular}{lll}
\hline & Surgical Oncology & CVT \\
\hline Number of positions & 46 & 140 \\
Number of applicants & 69 & 90 \\
Number of positions unfilled & 0 & $50(36 \%)$ \\
Number of applicants unmatched & $23(33 \%)$ & 0 \\
\hline
\end{tabular}

Source: SSO and NRMP.

ogy? It was very positive that three additional SSOaccredited training programs came online in time for the fellowship match this past year, with others in the planning stage. Nonetheless, we had to turn away many highly qualified individuals. Idea number three: we can determine future surgical oncology manpower needs utilizing currently available data, leading to a rational basis for continued increases in SSO-accredited surgical oncology fellowship training positions. Those of us in academic leadership roles, armed with this data, could approach our local powers-that-be to help garner the resources needed for increased surgical oncology fellowship positions.

A second emerging issue that is critical to our specialty, where the SSO has a major potential role to play, is the possibility of establishing board certification in surgical oncology. The past half-century has seen the unprecedented evolution of surgical specialties into their current status as discrete disciplines, with specialized knowledge, techniques, anatomic challenges, and diseases of focus. This is especially true in surgical oncology, which has attracted most of us due to its strong allure as a combination of the technical and the cognitive. For the past three decades the political waters have been less favorable for surgical oncology to be recognized as a distinct surgical specialty. However, there is an emerging understanding that the surgical oncologist has specialized knowledge that is not acquired in general surgical training: knowledge of the natural history of malignant disease, knowledge of multidisciplinary care for the cancer patient, and certainly, knowledge of how to perform some very unusual and technically demanding oncological operative procedures. These factors, coupled with an awareness of the rapidly increasing solid-tumor patient volume, have led to an active interest in creating a board certification mechanism for surgical oncology. Board certification in surgical oncology would impact on almost all of the issues we are discussing today. Certainly our identity as a surgical specialty would be reinforced in the eyes of trainees, Congress, other surgical societies, and the medical centers where we work. Predictably, the availability of board certification will increase the enthusiasm of young surgeons to pursue a career in this field. Further expansion, standardization, and upgrades of our already strong fellowship training programs can be anticipated to follow in short order. Board certification would also strengthen the position and impact of surgical oncologists practicing in the community, and might also aid in the development of comparable certification mechanisms in other countries from which we increasingly hope to draw SSO membership. Our SSO membership survey, conducted earlier this year, clearly demonstrates that more than two-thirds of our members want board certification in surgical oncology, and that they expect the SSO to help facilitate this possibility.

In our era of pay for performance, definable outcomes, and transparent quality-assurance programs, surgical oncology board certification would enable us to be more of a force to positively affect these concerns. For example, the American College of Surgeons National Surgical Quality Improvement Program (NSQIP), discussed in the Clinical Affairs Committee Forum yesterday, is the "first nationally validated, risk-adjusted, outcomes-based program to measure and improve the quality of surgical care. Medical centers and their surgical staff are able to use the data to make informed decisions regarding their continuous quality improvement efforts". 2 NSQIP includes 136 variables, and allows comparison of hospitals, specialties, procedures, and even surgeonspecific outcomes. Will outcomes data like this be used only by medical centers and their surgical staff? Ultimately, I think not. And so I draw your attention to the new NSQIP multi-specialty high-volume online calculator issued on February 7, 2007 (Fig. 6). Listed are the ten surgical specialties included in the NSQIP model; this list does not include surgical oncology. Would we perhaps have a more visible presence in the future if we were a board-certified specialty? Hopefully the Outcomes Task Force, newly created this past year, will help us in this critical endeavor. The Disparities Task Force, launched this past year, will also have a major role to play in this and many other significant issues about the adverse impact of disparities on cancer care and outcomes.

How board certification in surgical oncology will be implemented is the next order of business. The Directors of the American Board of Surgery, which includes several members of the SSO Executive Council, has unequivocally indicated that the time is ripe to begin this process in earnest. Several of us represent the SSO as members of the Surgical Oncology Advisory Council of the American Board of Surgery, and we are developing a multi-step action plan that will require much concerted effort by all of 


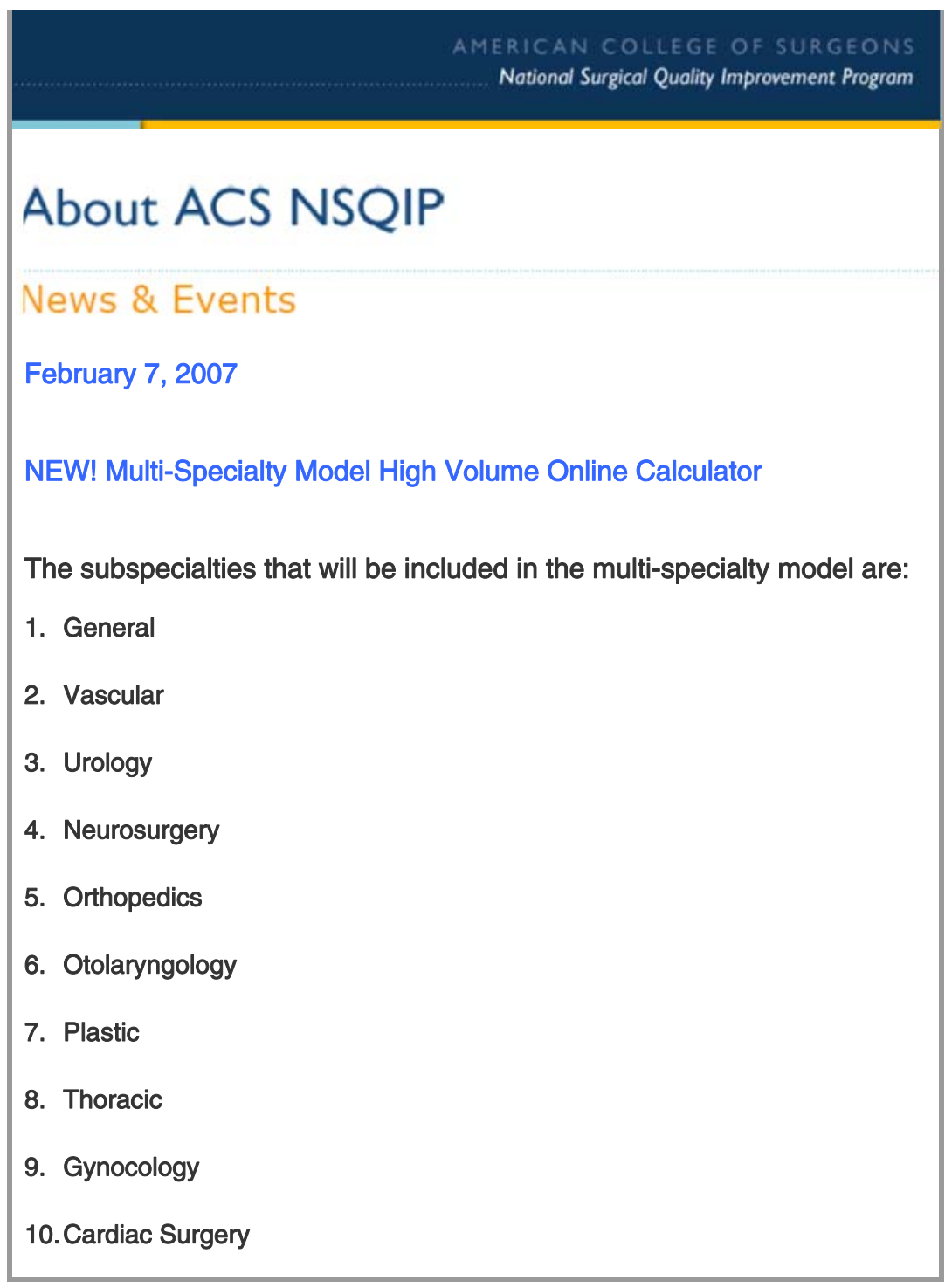

FIG. 6. Multi-specialty model high-volume online calculator. us to be successful. This process will take several years at a minimum, and will require our fellowships to be accredited by the American Council of Graduate Medical Education (ACGME). Once we have ACGME accreditation, the American Board of Surgery will be able to work with the SSO to develop board certification in surgical oncology. This past year we created a Board Certification Task Force, led by James Goodnight, to advise the SSO Executive Council while providing a direct communication link for you, the members of our Society. Please stay tuned!

A third major issue worthy of consideration is how to help the SSO become more inclusive, by vigorously embracing both US community surgical oncologists as well as surgical oncologists practicing abroad. To be honest, if we continue to view the SSO primarily as the domain of US academic surgical oncologists, we may well be undercutting our ultimate potential for influence. Expanded strength and vitality will come from inclusion and diversity and not by narrowness and exclusivity. You may disagree with me, but I believe that the hour is later than we think, and we should move aggressively now. To begin this effort, this year we created two new SSO Committees: the Community Surgical Oncology Committee and the International Surgical Oncology Committee. To make certain that these new committees can be heard loud and clear, their chairmen have been invited to become members of the SSO Executive Council. Why do we need to do this? Simply stated, if we want to affect the quality of surgical oncology care we must 
extend beyond our academic centers. Most cancer resections in the US are performed in the community. If surgical oncology is to provide leadership in contemporary multidisciplinary cancer care, we must embrace those surgeons who are providing the bulk of cancer surgery. This is important, not only to assure the public that they are receiving the highest quality of oncology care, but also for more specific tasks, for example, patient accrual to clinical trials such as those conducted by the American College of Surgeons Oncology Group (ACOS/OG). Over the past 12 months, the SSO has forged a strategic partnership with ACOS/OG to help reach mandated patient accrual targets needed to successfully renew National Cancer Institute (NCI) funding. We all have a critical stake in the success of ACOS/OG; were it to fail, it is very unlikely that another National Institutes of Health (NIH)-funded surgical oncology "trialist" group will ever emerge.

There are other reasons why this is important to do. In many community hospitals, the link between surgical volume and outcomes feeds a vicious cycle, fueled by the tort reform crisis, where the surgical staff is under pressure to refer the more difficult cases to the cancer centers, leading to the erosion of surgical oncology skills in the community, which in turn will lead to even more referrals to the centers. And those of us in the cancer centers know that, with our typical 85$90 \%$ inpatient occupancy rates, we may not be able to easily absorb large additional referral volumes. Board certification could help stabilize this trend. It could also better position community surgical oncologists vis-à-vis other oncology specialists as well as hospital administrations that only variably respond to our professional needs. As you can see, these problems intertwine, but as the old Chinese proverb goes: "Within a problem lies the seeds of a solution". For sure, this is not a time for complacency.

Why should we be more aggressive in engaging the international surgical oncology community? In this era of pervasive globalization, with near-instantaneous information transfer via the Internet, we are now truly tied together as a global village, as Marshall McLuhan predicted 30 years ago. If we do not embrace this reality, we will be missing a remarkable opportunity to help fill the organizational leadership gap in international surgical oncology. Already we have a long tradition of international membership, with members from 41 countries at the last count. Compare this to the American Society of Clinical Oncology (ASCO), for example, which over the past 25 years has increased in size from 3000 to 25,000 members from 110 countries, and our own potential for international surgical oncology growth and leadership becomes apparent. But to come back to the original question: why should we do this? And I answer as follows: we in the US do not have a monopoly on surgical innovation, and we can either read about new approaches being developed in other countries or facilitate the SSO as the disseminator of these advances - it is our choice at this point, although the window of opportunity will not remain open forever. We have many lessons to learn from our overseas colleagues. Accruing patients to clinical trials, we must be candid, has generally been done much better abroad than here. We could learn from the European Organisation for Research and Treatment of Cancer (EORTC), for example, rather than continue to excuse ourselves from this responsibility. The SSO could become the major international forum where the important discussions and debates take place. As an example, consider our relatively modest impact, as an organization, on the international trials-based debate about the extent of nodal dissection for gastric cancer that has occurred over the past 20 years. Without elaborating further, I think that you get the gist of my point. Another important area where an enhanced international presence might be very useful is in international oncology education. This endeavor would be natural for a more internationally flavored SSO. In the past, efforts led by Hugo Villar, Charles Balch, and others, initially under the aegis of the American College of Surgeons Commission on Cancer, and more recently via the International Education Committee of ASCO, were very well received. Once again this important international oncology education program is without a sponsoring organizational home, and the SSO could help as part of an expanded international presence. Working with a broader membership base, a mix of US and international surgical oncologists could serve as educational teams that could reach many underserved locations throughout the world, where such efforts are badly needed and would be deeply appreciated.

All of these many activities could be accomplished by an enlarged SSO membership of more diverse phenotype. I am certain that this can happen without negatively affecting - but instead positively extending - our mission and vision as the Society of Surgical Oncology. In addition, a broadened membership base will also directly benefit the SSO, not only due to enhanced membership dues revenue, but also because of the power inherent in a diverse organization with the throw-weight of several thousand more members, positioned to speak on behalf of surgical oncologists everywhere. 
This process has been jump-started this year by the creation of the Community and the International Surgical Oncology Committees, with guaranteed representation on the SSO Executive Council. A necessary next step will be to revise our SSO membership, which currently has several different categories, and replace it with one designation, called "member", with identical privileges of membership for all members - period!

I would like to discuss one final opportunity for the SSO. How can we be best positioned to fully participate in the molecular-based revolution in oncology? This is rapidly leading to clinical deployment of nontoxic, personalized oncology therapeutics based on high-throughput assessment of patient and tumor biomarkers. If we do not vigorously participate in this as committed stakeholders, a remarkable opportunity will pass us by, and ultimately our role in multidisciplinary cancer care can be predicted to shrink as well. It is tremendously exciting to work in a field where the knowledge base is expanding exponentially, and where there are major opportunities to partner with other oncology specialists, using our complementary expertise, on behalf of our shared patients. At the same time, it is important to keep in mind that we are usually the first oncologist to see a patient, and that we will have first access to the tumor tissues so vital to contemporary molecularly oriented oncology research. These are very powerful "firsts"! It is especially gratifying that so many young surgical oncologists want to acquire the investigative skills needed for preclinical translational research and clinical trials testing. Almost certainly, this can lead to an expanded cadre of surgical oncologists who are able to develop and administer personalized molecularly targeted onco-therapeutics. To facilitate this possibility, this past year the SSO leadership has begun to engage "Big Pharma" in a concerted effort to create clinician-investigator awards, the so-called CIA program. With a rapidly growing inventory of non-toxic molecules and biological therapies, many administered orally, "Big Pharma" recognizes that surgical involvement will also be essential in designing new trials that have "surrogate biological endpoints". Upon maturity, the CIA program will annually fund ten or more additional young surgical oncologists. I am delighted to be able to report that three CIA awards are being given this year, hopefully with more in the pipeline for next year. Many thanks to the SSO Fellowship and Research Grant Committee, led by James Economou, and to the many other members of the SSO, especially Charles Balch, Kelly McMasters, and Nick Petrelli, who participated in fund raising trips and dialogue with "Big Pharma". Without their efforts this new program would not have got off the ground.

So we come to the end of my story about these four magnificent opportunities for our Society. But this is really the just the take-off point from which we must go forward. How to coalesce these initial efforts into a course of action? As Yogi Berra, the famous baseball player of the New York Yankees, once said: "You got to be careful if you don't know where you're going, because you might not get there". With this admonition in mind, we began with an SSO membership survey last spring to learn more about your feelings on these issues. This segued into an SSO Executive Council retreat last summer, out of which came a revised SSO mission and vision statement and new SSO strategic plan, an effort last undertaken in 1991 (Table 3). This strategic plan can be a blueprint for our future actions, and is worth a careful personal study. See if it speaks to your needs as a member of the SSO. Contained within it are many strategic opportunities that will enable each of us to become even more fully involved. In my waning moments as

TABLE 3. SSO Strategic Plan 2007-2010. Approved 10-9-06

Goal 1 - Multi-specialty member needs

SSO will provide for professional needs of its multi-specialty membership, both domestic and international.

Goal 2 - Education and training

SSO will provide continuing education, training and workshops designed to meet the needs of its diverse membership.

Goal 3 - Clinical and translational research

SSO will promote high-quality clinical and translational research in surgical oncology, with a focus on clinical trials and outcomes research.

Goal 4 - Career development

SSO will help new surgical oncology specialists and trainees establish productive careers and practices, both in academic and community settings.

Goal 5 - Quality of cancer care and practice management

SSO will strive to enhance the quality of life and survival of the surgical patient with cancer, and improve the practice environment in which high-quality surgical oncology care is delivered.

Goal 6 - Governance and operations

SSO will optimize its organizational vitality, its operational excellence, and its technological capacity. 
your President, I would like to thank you for the privilege of leadership that you have bestowed on me this past year, a defining moment in my surgical oncology career. I will leave you with the words of Alexander Graham Bell: "Great discoveries and improvements invariably involve the cooperation of many minds". Working together I am certain that we can make things better. It's been a great year. Thank you for your trust and your attention.

\section{REFERENCES}

1. Debas HT, Bass BL, Brennan MR, Flynn TC, Folse R, Freischlag JA, Friedmann P, Greenfield LJ, Jones RS, Lewis FR, Malangoni MA, Pellegrini CA, Rose EA, Sachdeva AK, Sheldon GF, Turner PL, Warshaw AL, Welling RE, Zinner MJ. American Surgical Association Blue Ribbon Committee report on surgical education: 2004. Ann Surg 2005; 241:1-8.

2. American College of Surgeons National Surgical Quality Improvement Program. About ACS NSQIP. https://acsnsqip.org/main/about_overview.asp, 2007. 